DOI: 10.14451/1.182.60

\title{
ОЦЕНКА РЕАЛИЗАЦИИ ИМПОРТОЗАМЕЩЕНИЯ В РОССИИ В КОНТЕКСТЕ ДИНАМИКИ ИМПОРТА
}

\author{
(c) 2020 Зюкин Данил Алексеевич \\ кандидат экономических наук \\ Курская Государственная сельскохозяйственная академия имени И.И. Иванова, Россия, Курск \\ E-mail: nightingale46@rambler.ru \\ (c) 2020 Быстрицкая Анна Юрьевна \\ кандидат экономических наук \\ Курский Государственный университет, Россия, Курск \\ E-mail anet46bystr@mail.ru \\ (c) 2020 Белова Татьяна Валентиновна \\ кандидат экономических наук \\ Курский Государственный университет, Россия, Курск \\ E-mail: tv_belova@mail.ru. \\ (C) 2020 Зубкова Татьяна Алексеевна \\ старший преподаватель \\ Курский институт кооперации (филиал) Белгородского университета кооперации, \\ экономики и права, Россия, Курск \\ 305004, Россия, Курск, улица Радищева, д. 116 \\ E-mail: zubkovat999@yandex.ru \\ (c) 2020 Гребнева Марина Евгеньевна, \\ кандидат сельскохозяйственных наук \\ Курский Государственный университет, Россия, Курск \\ E-mail: Mgrebneva@mail.ru
}

В статье рассматривается проблема реализации импортозамещения в России, не позволяющая полноценно восполнить нишу, возникшую из-за сокращения импортных поставок. В исследовании показано с помощью анализа изменения динамики импорта основных партнеров и товарной структуры, что основными причинами изменений величины импорта в 2014-2018 гг. стали внешнеполитические противоречия и структурный кризис в экономике страны, ставшие причиной значительной девальвации рубля и снижения покупательной способности российских субъектов.

Ключевые слова: внешняя торговля России, импорт, товарная структура импорта, структурный кризис в экономике, санкции, импортозависимость, импортозамещение.

Проблема импортозамещения в России приобрела особую актуальность на волне изменения политической конъюнктуры в 2014 году, когда на фоне конфликта в Украине страны Евросоюза и США ввели целый перечень санкций, направленных на экономические и политические ограничения нашей страны. Данные антироссийские мероприятия, в первую очередь, коснулись экономики РФ, способствуя снижению темпов ее развития и возникновению предпосылок к экономическому кризису. Как следствие, это привело к снижению реальных доходов населения, росту безработицы, уровня инфля- ции и возникновения дефицита определенных товаров. Это связано с тем, что обострение политических противоречий способствовало и ухудшению сформированных ранее глубоких внешнеторговых интеграционных связей. В угоду антироссийскому политическому курсу, который несет значительный финансовый ущерб для бизнеса многих европейских предприятий, темпы и объемы внешней торговли РФ в основными странами-партнерами были значительно снижены [1, 2].

В условиях политической нестабильности вопрос обеспечения национальной безопас- 
ности и автономности РФ приобретает особую актуальность, что стало очевидно в условиях санкционного давления. Поэтому развитие импортозамещения по всем основным направлениям стало первоочередной задачей, достижение которой имеет стратегическое значение, но, вместе с тем, продолжается сталкиваться с рядом трудностей. Основной причиной высокой импортозависимости страны является низкая конкурентоспособность отечественной продукции по многим отраслям по сравнению с импортными аналогами, что зачастую обусловлено технологическим отставанием России от более развитых в данном направлении стран. Например, в части лекарственного обеспечения, являющегося одной из основных проблем импортозависимости, отечественный фармацевтический рынок более чем на 70\% сформирован за счет ввозимых из ЕС импортных лекарственных средств, в первую очередь, Германии и Индии [3]. Данная проблема не решена и сейчас, поэтому развитие отечественного промышленного и продовольственного потенциала, с целью повышения конкурентоспособности отечественных товаров в рамках реализации стратегии импортозамещения является одной из наиболее актуальных экономических и политических задач [4, 5].

С использованием данных статистического сборника «Россия в цифрах» в ходе исследования проведен сравнительный анализ динамики и структуры импорта в РФ в 2014 и 2018 гг. с целью выявления произошедших за период политического и экономического кризиса из- менений, связанных с реализацией стратегии импортозамещения. В качестве базисного был выбран 2014 год, поскольку отражает состояние внешней торговли РФ в докризисный период.

Общий объем импорта в РФ в исследуемом периоде имеет волнообразный характер вариации, который хорошо описывается параболической моделью регрессии. Так, в период 20142016 гг. общий объема импорта в РФ неуклонно снижался, достигнув 182 млрд. долл., что является минимальным значением за последние 5 лет и соответствует уровню до мирового финансового кризиса. В 2017-2018 гг. тенденция сменилась на положительную - объем импорта начал увеличиваться, достигнув величины в 238 млрд. долл., однако это по-прежнему меньше уровня 2014 года на 49 млрд. долл. (рисунок 1).

В этой ситуации становится важным понимание причины происходящих изменений в 2017-2018 гг.: является ли фактическое увеличение объема импорта относительно уровня 2015-2016 гг. следствием реализации импортозамещения или возврат к докризисному уровню сдерживает неблагоприятная экономическая ситуация внутри страны и политическая обстановка. На наш взгляд, основным фактором является все же изменение в 2014 году политической конъюнктуры, в результате чего рядом стран был введен и продолжает расширяться пакет антироссийских экономико-политических санкций, который коснулся многих элементов внешнеторговой деятельности, способствую усугублению внутриэкономического кризиса в стране. Вторым приоритетным фактором сни-

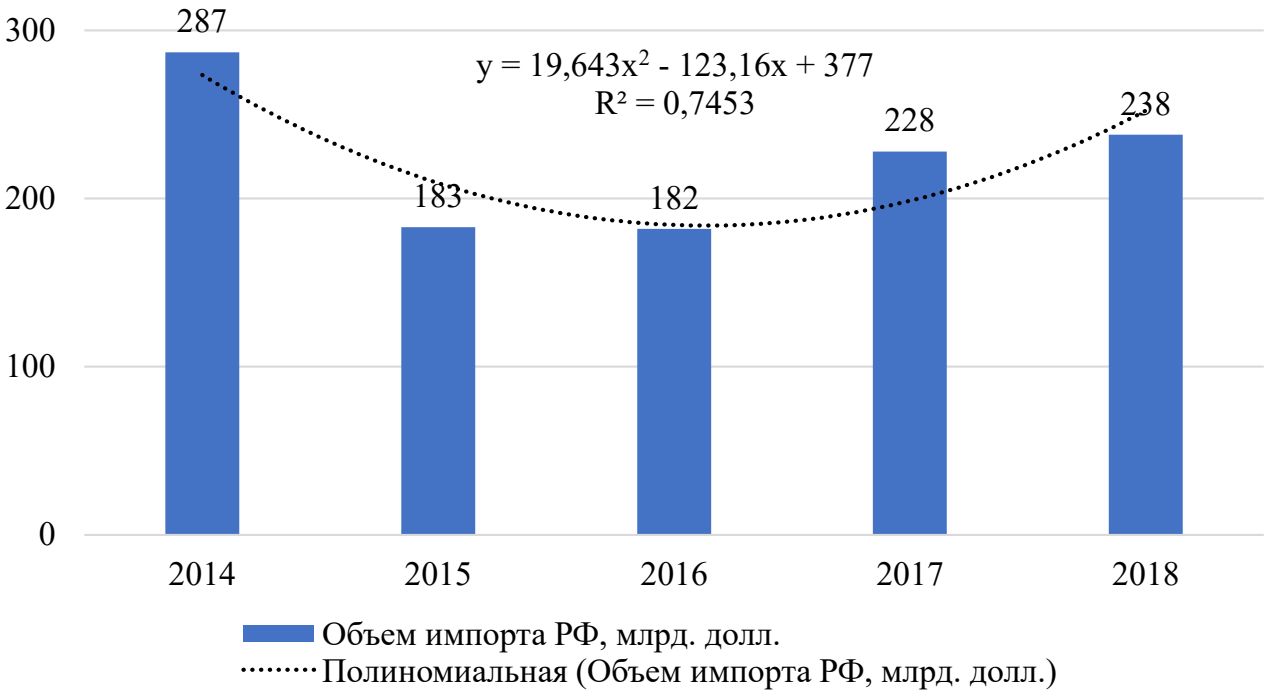

Рисунок 1. Динамика общего объема импорта в РФ в 2014-2018 гг. 
жения импорта является внутриэкономическая проблема, повлекшая сильную девальвацию рубля, в результате чего импортная продукция на российском рынке потеряла конкурентоспособность. Одним из способов подтвердить указанные нами два тезиса является анализ изменений к 2018 году величины импорта в Россию с основными странами-импортерами по состоянию на 2014 докризисный год.

Анализ данных показал, что пятерка странлидеров по импорту в Россию (Китай, Германия, США, Беларусь и Италия) является устойчивой и не изменилась за изучаемый период. Однако все они в той или иной степени вне зависимости от политических отношений сократили импортные поставки в Россию. Китай, как в 2014-м, так и в 2018-м годах, является безусловным лидером по объему импорта в РФ, величина которого имеет значительный отрыв по сравнению с уровнем других стран. При этом, в изучаемый период поставки пострадали минимально - сокращение составило 1,55 млрд. долл. или 2,9\%. Снижение величины импорта из Китая является наименьшей среди десятки основных партнеров РФ, что подчеркивает тот факт, что изменение внешнеторговой конъюнктуры в 2014 году практически не оказало влияние на его позицию ключевого импортера. Также минимально экономико-политические проблемы России затронули процессы импорта из Белорусии, объем которого сократился на 4,5\% и по состоянию на 2018 год и сопоставим теперь с США. А вот экономические отношения России с основными Европейскими партнерами и США серьезно по- страдали. В результате, объем импорта из Германии в абсолютном выражении сократился более всего среди всех стран - на 7,5 млрд. долл., однако в относительном выражении импорт из США претерпел самое значительное снижение среди топ-5 - на 32,3\%, т.е. почти на треть, тогда как импорт из Германии - на 22,6\%, а из Италии на $16,9 \%$.

Остальные импортеры свои позиции в 2018 году в сравнении с 2014 годом изменили, при этом увеличения объемов импорта в России также ни в одной стране не произошло. Украина и Великобритания - наиболее активные противники России на мировой политической арене, что сильно влияет на их экономические отношения с нашей страной, результатом чего стало практически двукратное сокращение импорта в Россию. Тем не менее, и сегодня объем импорта в РФ из Украины является значительным (5,5 млрд. долл. в 2018 году), что обусловлено территориальной близостью стран и наличием многолетних внешнеторговых связей, поэтому Украина по-прежнему по состоянию на 2018 год входит в десятку основных импортеров в Россию, в то время как Великобритания уже нет. Франция является единственной страной, которая улучшила свое место среди основных импортеров, так как сокращение импорта было меньшим, чем с Украиной и Японией, которая как и Корея, не смотря на объявленный на политическом уровне разворот России на Восток, сократили торговые отношения с нашей страной (таблица 1).

Оценка товарной структуры импорта РФ, от-

Таблица 1. Изменения в импортных отношениях с десятью основными импортерами продукции в России в 2014-2018 гг.

\begin{tabular}{|c|c|c|c|c|c|c|c|}
\hline \multirow{3}{*}{ Страна } & \multicolumn{2}{|c|}{2014 г. } & \multicolumn{2}{|c|}{2018 г. } & \multicolumn{3}{|c|}{ Изменение в 2018 г. к 2014 г. } \\
\hline & \multirow{2}{*}{$\begin{array}{l}\text { Величина } \\
\text { импорта, } \\
\text { млн. долл. }\end{array}$} & \multirow{2}{*}{$\begin{array}{c}\text { Место в } \\
\text { структуре } \\
\text { импорта } \\
\text { России }\end{array}$} & \multirow{2}{*}{$\begin{array}{l}\text { Величина } \\
\text { импорта, } \\
\text { млн. долл. }\end{array}$} & \multirow{2}{*}{$\begin{array}{c}\text { Место в } \\
\text { структуре } \\
\text { импорта } \\
\text { России }\end{array}$} & \multicolumn{2}{|c|}{ величины импорта } & \multirow{2}{*}{$\begin{array}{c}\text { места в } \\
\text { структуре } \\
\text { импорта } \\
\text { России }\end{array}$} \\
\hline & & & & & Млн. долл. & $\%$ & \\
\hline Китай & 53773 & 1 & 52218 & 1 & -1555 & $-2,9$ & 0 \\
\hline Германия & 32975 & 2 & 25511 & 2 & -7464 & $-22,6$ & 0 \\
\hline США & 18496 & 3 & 12516 & 3 & -5980 & $-32,3$ & 0 \\
\hline Беларусь & 12750 & 4 & 12179 & 4 & -571 & $-4,5$ & 0 \\
\hline Италия & 12729 & 5 & 10580 & 5 & -2149 & $-16,9$ & 0 \\
\hline Япония & 10908 & 6 & 8819 & 7 & -2089 & $-19,2$ & -1 \\
\hline Украина & 10750 & 7 & 5461 & 9 & -5289 & $-49,2$ & -2 \\
\hline Франция & 10630 & 8 & 9558 & 6 & -1072 & $-10,1$ & 2 \\
\hline Корея & 9030 & 9 & 7009 & 8 & -2021 & $-22,4$ & 1 \\
\hline Великобритания & 7809 & 10 & 4037 & 13 & -3772 & $-48,3$ & -3 \\
\hline
\end{tabular}

Источник: рассчитано автором по данным сборника «Россия в цифрах» [6] 
сортированной в порядке убывания значения, показала устойчивую тенденцию сокращения величины импорта по всем продуктовым направлениям. Машины, оборудование и транспортные средства составляет основу всех импортируемых в РФ товаров, объем импорта которых в 2018 году составил более 113 млрд. долл., что на 17,5\% ниже уровня 2014 года. Вторым по значимости является импорт продукции химической промышленности и каучука (43,6 млрд. долл. в 2018 году), величина ввоза которых является относительно устойчивой по сравнению с уровнем 2014 года, поскольку за 5 лет снижение объема импорта составило всего лишь 6,2\% или 2,9 млрд. долл. Импорт продовольственных товаров в РФ сократился за 5 лет на $26 \%$ или 10,4 млрд. долл., при этом это одно из тех направлений, где сокращение импорта дало хорошие возможности российским производителям [7]. Объем ввоза металлов и драгоценных камней, составлявший в 2014 году 20,6 млрд. долл., за 5 лет сократился до 17,8 млрд. долл. (снижение составило 13,6\% или 2,8 млрд. долл.). Незначительное снижение $(-9,2 \%)$ отмечается в величине импорта текстиля, текстильных изделий и обуви, объем которого в 2018 году составил 14,8 млрд. долл. в сравнении с 16,3 млрд. долл. на начало рассматриваемого периода. Объем импорта прочих товаров за 5 лет снизился с 12,7 млрд. долл. до 9,5 млрд. долл., что равно 25,2\%. Объем ввоза минеральных продуктов, составлявший в 2014 году 7,5 млрд. долл., к 2018 году сократился на 31,5\% и достиг 5 млрд. долл. В наибольшей степени $(-33,9 \%)$ сократилась величина импорта древесины и целлюлозно-бумажных изделий, суммарный объем ввоза которых в 2018 году составил 3,9 млрд. долл. в сравнении с 5,9 млрд. долл. в 2014 году. Наименьшая величина импорта в РФ отмечается для такой категории товаров, как кожевенное сырье, пушнина и изделия из них, объем ввоза которых хоть и варьировал в период 2015-2017 гг., однако в 2018 году, как и на начало рассматриваемого периода, составлял 1,3 млрд. долл. (таблица 2).

По состоянию на 2018 год, не смотря на различную динамику сокращения импорта, его основу, как и прежде, составляют машины, оборудование и транспортные средства, доля которых в структуре импорта колеблется в пределах 47-48\%. В общей товарной структуре импорта второй по величине является продукция химической промышленности и каучук, удельный вес которых равен $18,3 \%$, а третьей - производственные товары и сельскохозяйственное сырье $(12,4 \%)$. Доля металлов и драгоценных камней в 2018 году была равна 7,5\% от общего объема импорта в РФ, а текстиля $-6,1 \%$. Все прочие импортируемые товары суммарно составили $8,2 \%$

Таблица 2. Динамика товарной структуры импорта РФ в 2014-2018 гг.

\begin{tabular}{|l|c|c|c|c|c|c|c|}
\hline \multirow{2}{*}{ Показатель } & \multicolumn{3}{c}{ Значение, млрд. дол. } & \multicolumn{2}{c|}{ Изменение 2018 г. к 2014 г. } \\
\cline { 2 - 8 } & 2014 & 2015 & 2016 & 2017 & 2018 & $\begin{array}{c}\text { Млрд. } \\
\text { долл. }\end{array}$ & \% \\
\hline Объем импорта всего, в т.ч.: & 287,0 & 183,0 & 182,0 & 228,0 & 238,0 & $-49,0$ & $-17,1$ \\
\hline $\begin{array}{l}\text { - машины, оборудование и транс- } \\
\text { портные средства }\end{array}$ & 137,0 & 81,9 & 86,2 & 110,0 & 113,0 & $-24,0$ & $-17,5$ \\
\hline $\begin{array}{l}\text { - продукция химической промыш- } \\
\text { ленности, каучук }\end{array}$ & 46,5 & 34,0 & 33,8 & 40,3 & 43,6 & $-2,9$ & $-6,2$ \\
\hline $\begin{array}{l}\text { - продовольстенные товары и } \\
\text { сельскохозяйственное сырье (кроме } \\
\text { текстильного) }\end{array}$ & 40,0 & 26,7 & 25,1 & 28,9 & 29,6 & $-10,4$ & $-26,0$ \\
\hline $\begin{array}{l}\text { - металлы, драгоценные камни и } \\
\text { изделия из них }\end{array}$ & 20,6 & 12,4 & 11,9 & 16,3 & 17,8 & $-2,8$ & $-13,6$ \\
\hline - минеральные продукты & 7,3 & 5,0 & 3,2 & 4,5 & 5,0 & $-2,3$ & $-31,5$ \\
\hline $\begin{array}{l}\text { - древесина и целлюлозно- } \\
\text { бумажные изделия }\end{array}$ & 5,9 & 3,6 & 3,4 & 3,6 & 3,9 & $-2,0$ & $-33,9$ \\
\hline $\begin{array}{l}\text { - кожевенное сырье, пушнина и } \\
\text { изделия из них }\end{array}$ & 1,3 & 0,8 & 0,8 & 1,1 & 1,3 & - & - \\
\hline $\begin{array}{l}\text { - текстиль, текстильные изделия и } \\
\text { обувь }\end{array}$ & 16,3 & 10,8 & 11,0 & 13,6 & 14,8 & $-1,5$ & $-9,2$ \\
\hline - прочие & 12,7 & 7,7 & 7,1 & 8,7 & 9,5 & $-3,2$ & $-25,2$ \\
\hline
\end{tabular}

Источник: рассчитано автором по данным сборника «Россия в цифрах» [6] 
в общей структуре импорта РФ.

Таким образом, проведенное исследование показало, что стратегия импортозамещения в России полноценной реализации не получила, о чем свидетельствует наращивание объема импорта в 2017-2018 гг., после его сокращения в 2015-2016 гг. Данная тенденция характерна для всех видов продукции, представленных в товарной структуре импорта. Это свидетельствует о том, что и сегодня Россия сохраняет значительную импортозависимость по ряду направлений, преодолеть которую в современных условиях не получилось. Сокращение объема импорта определяется ухудшением политических отношений, которые проявились в форе экономических санкций, препятствующих развитию внешнеторговых отношений между Россией и целым рядом стран.

Отсутствие фундаментального сдвига в сторону решения проблемы диверсификации партнеров по импорту подтверждает и оценка в контексте изменения основных партнеров которая отразила относительную стабильность ситуации - из первой десятки выпала только Великобритания, а пятерка основных партнеров РФ по импорту в 2018 году в сравнении с 2014 годов не изменилась. Безусловным лидером по импорту в РФ является Китай, объем ввоза товаров из которого сегодня составляет свыше 52 млрд. долл., что превышает Германию, ближайшего партнера по импорту, более чем в 2 раза. Европейские партнеры и США сократили объем импорта в Россию, однако это не привело к развитию экономических отношений с азиатскими странами. Значимого прогресса в динамике (наращивание импорта свыше 1 млрд. долл.) удалось достигнуть только с Вьетнамом, тогда как с основными партнерами в этом макрорегионе мира - Китаем, Японией и Кореей, происходит снижение импортного потока, причем относительно двух последних стран показатель сократился на $19 \%$ и 22\%. Таким образом, заявленный разворот экономической политики России на Восток трудно назвать состоявшимся, а снижение импорта со всеми основными партнерами имеет общий базис - значительная девальвация рубля и снижение покупательной способности российских партнеров. Со странами, с которыми возникли политические противоречия, динамика снижения импорта сильнее.

Товарная структура импорта РФ также является стабильной, несмотря на то, что отмечается снижение объёмов ввоза товаров по всем категориям. Как и прежде, подавляющая доля импорта (47-48\%) включает машины, оборудование и транспортные средства, а изменения этого направления пропорциональны показателю с импортом в целом. Одной из наиболее популярных направлений импортозамещения стало продовольствие, однако развитие отечественного АПК не значительно повлияло на снижение доли продовольственных товаров - с $13 \%$ до $12,4 \%$, что соответствует общим трендам снижения импорта по другим товарам. Увеличение объемов импорта в условиях улучшения состоянии экономики России свидетельствует о сохранении импортозависимости, преодолеть которую пока не удалось. Отрицать позитивных подвижек в развитии ряда отраслей экономики России нельзя, однако коренного сдвига в системе внешнеторгового товарооборота не произошло, и наша страна также продолжает закупать в значительных объемах за границей продукцию машиностроения, химической промышленности и продовольствия, экспортирую взамен в основном природные ресурсы и сырье.

\section{Библиографический список}

1. омарских А.Н. Проблемы и потенциал импортозамещения в России // Студенческий вестник. 2017. № 5-2 (5). С. 34-37.

2. Аблязова А.И., Клевцов О. И., Мухаметов Д.А. Политика Российской Федерации в сфере импортозамещения: проблемы и пути совершенствования // Аллея науки. 2017. № 7. С. 629-632.

3. Бушина Н.С., Зюкин Д.А. Методический подход к оценке конкурентоспособности подразделений аптечной сети // Международный журнал прикладных и фундаментальных исследований. 2015. № 12-6. С. 10911095.

4. Валуев И.И., Шпак А.С. К вопросу о проблемах импортозамещения в России // Научный альманах. 2016. № 10-1 (24). С. 63-66.

5. Галкина Л.А., Шарипов А.И. Тенденции, тренды и проблемы развития процессов импортозамещения в России // Новая наука: финансово-экономические основы. 2017. № 1. С. 91-100.

6. Россия в цифрах. 2019: Крат.стат.сб./Росстат- М., 2019-549 с. 
7. Соловьева Т.Н., Пожидаева Н.А., Зюкин Д.А. Государственное регулирование и импортозамещение продовольственной продукции: проблемы и решения // Экономика сельскохозяйственных и перерабатывающих предприятий. 2016. № 11. С. 17-20. 